
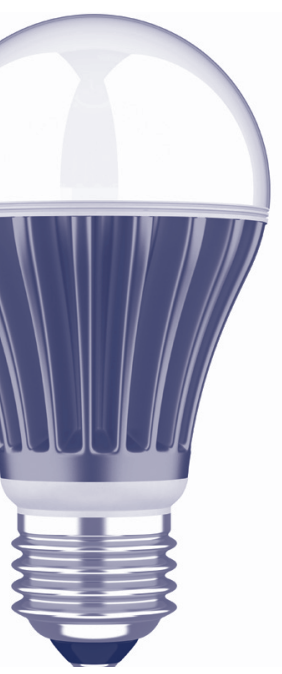

\section{Technology Wins!}

Recently, Jefferson's Board approved \$11 million to develop and install a major energy engineering effort throughout the campus.

This is a continuation of the commitment the Board has made to improve energy on our campus. In the last 19 years, Jefferson has saved more than $\$ 132$ million in energy. This is the equivalent of planting 84,000 trees.

The project team's approach will be to use the latest technology available and to also apply it in an innovative way.

One example of this approach will be the use of occupancy sensors in an entire new way. Not only will these sensors turn off lights in unoccupied areas, but they will also send a signal to our building control system to turn down the volume of air going to the unoccupied space, thus reducing the use of electricity and steam.

We will also be installing the latest in lighting technology, high efficient light bulbs and LED fixtures. In the Bluemle Life Science Building, we will be installing sensors and variable motor controls to operate all of our cooling equipment at maximum efficiency. In the Gibbon, we will be generating electricity by running high pressure steam through a micro turbine. This steam reduction is currently done with mechanical pressure reduction valves, which means we will be getting our electricity for a fraction of a penny. This will run around the clock 24/7.

When all of the projects have been installed, we will save more than $\$ 2.2$ million per year which is the environmental equivalent of taking 2,167 cars off the road.

EARTH DAY Wednesday, April 22, 11 a.m. -1 p.m., Lubert Plaza

Come out and celebrate with us!

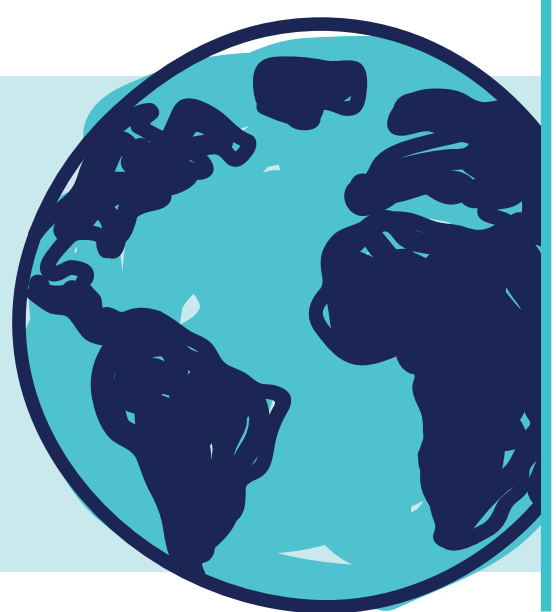

ON THE HOME FRONT

\section{Don't let your money and your} hot water go down the drain.

Most of the domestic hot water used in this country is for cleaning ourselves, our clothes, dishes and our pets and is usually stored in tanks. When these systems fail and require replacement, there are two types to consider conventional and tankless.

For most Americans, tankless is a relatively new technology, operating only as hot water is needed on demand. As soon as the demand rises, the unit heats the water and there is no storage. While unconventional here, these tankless systems have been widely used overseas for decades.

Tankless systems cost more to purchase and install but they save energy (more efficient), last longer (20 years vs. 10 years) save space and give continuous hot water.

The tankless may require larger gas piping (or switching to electricity) due to the large instantaneous energy requirement.

If you plan to stay a while in your house, it may make sense to purchase a tankless heater. By far, the best reason to have a tankless water heater is for the endless supply of water that it provides.

\section{A Bonanza of Savings}

When one's compact fluorescent lamps (CFL) need replacing, install light-emitting diodes (LED). And if one's lamps being replaced are incandescent, don't even think, just Install LEDs. DO IT. 


\section{Jefferson.}

Energy Services Department

214 South 11th Street, Room 400

Philadelphia, PA 19107

\section{Gurrents}

SPRING 2015

\section{Where does our heat come from?}

Earlier this year, as we shivered moving around campus in single-digit temperatures, we were grateful for the steam that heated our buildings. Our gratitude swelled when one added in the year round steam that is used for sterilization, humidification and domestic hot water production.

But where is the plant that is sufficiently formidable to generate and supply all of this steam on a year-round basis? One searches skyward, seeking telltale signs, such as fuel tanks, exhaust stacks, chimneys etc. but finds no clues. To solve this mystery, one must first look westward to 25th and Grays Ferry Avenue and then, at that point, go underground to learn the answers.

Our local District Energy Company, Veolia Energy, uses a sophisticated array of boilers, duct burners, valves, etc. to make steam and deploy it - all underground - to obtain maximum plant efficiently.

There are over 300 customers on 26.1 miles of steam and chilled water distribution piping, overseen by the Public Utility Commission.

Last year, steam costs here totaled $\$ 4.4$ million.

\section{DR. WATTS' BRILLIANT SAVINGS}

\section{Nothing succeeds like "OFF"}

Kenny Rookstool, Facilities Services Plant Operation Mechanic is seen here accepting his award for his suggestions around the JHN Building. He noticed that a lot of exterior lighting was left on during the daylight hours. Light sensors have been installed and the lighting changed to LED bulbs, saving even more money.

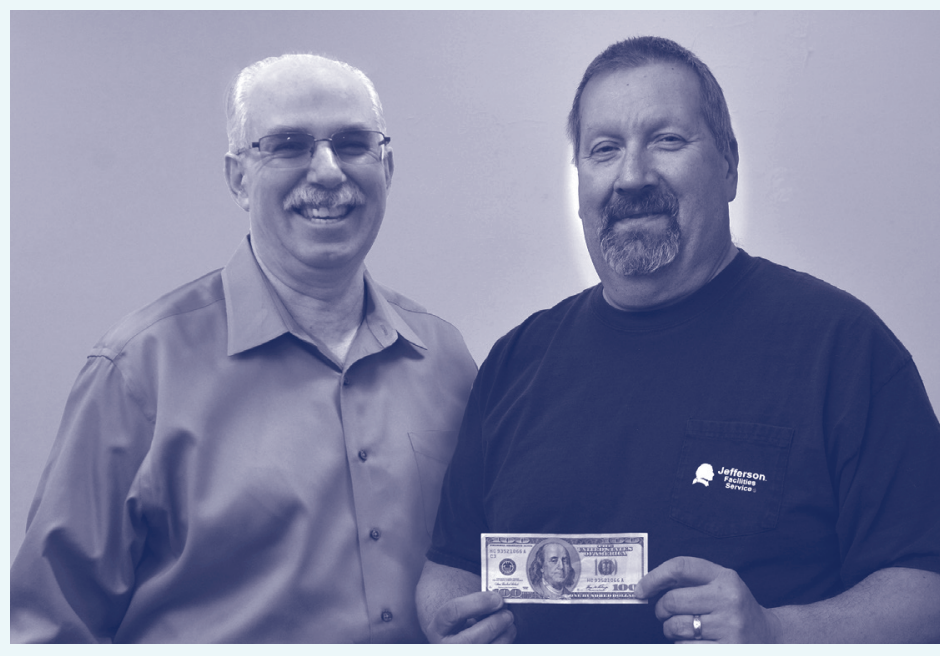

Kenny Rookstool, Facilities Services Plant Operation Mechanic, accepting his $\$ 100$ bill from Randy Haines, CEM, Energy Manager.

\section{Have an Energy Saving Idea?}

\section{Contact me at Randolph.Haines@jefferson.edu}

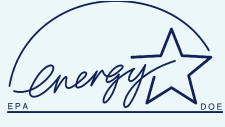

Look for the EPA's Energy Star label on products that use less energy, save money on your utility bills and help protect the environment 